\title{
Caripyrin, a new inhibitor of infection-related morphogenesis in the rice blast fungus Magnaporthe oryzae
}

\author{
Patrick H Rieger ${ }^{1}$, Johannes C Liermann ${ }^{2}$, Till Opatz ${ }^{2}$, Heidrun Anke ${ }^{1}$ and Eckhard Thines ${ }^{1}$ \\ Caripyrin (trans-5-(3-methyloxiranyl)pyridincarboxylic acid methyl ester, 1), a new pyridyloxirane, was isolated from submerged \\ cultures of the basidiomycete Caripia montagnei. The compound was found to inhibit conidial germination and appressorium \\ formation in the rice blast fungus Magnaporthe oryzae, whereas the infection-related morphogenesis in several other \\ phytopathogenic fungi was not affected. In plant assays on rice, 1 was found to protect plants more efficiently against fungal \\ infection than the structurally related fungal secondary metabolite, fusaric acid. Contrary to the latter, 1 was neither cytotoxic, \\ antibacterial, nor nematicidal.
}

The Journal of Antibiotics (2010) 63, 285-289; doi:10.1038/ja.2010.31; published online 9 April 2010

Keywords: antifungal activity; basidiomycetes; Caripia montagnei; caripyrin; Magnaporthe oryzae; plant protection; pyridyloxirane

\section{INTRODUCTION}

Crop losses world wide due to plant diseases are estimated to account for almost $20 \%$ of the major food and cash crops produced. ${ }^{1}$ Among the plant diseases caused by fungal pathogens, rice blast, caused by Magnaporthe oryzae, is the most serious disease that infects cultivated rice and therefore a threat to the world's most important food security crop. $^{2}$ To enter and colonize the host plant, M. oryzae displays a remarkable morphological and physiological specialization. During the prepenetration phase, the germ tube differentiates into a melanized dome-shaped appressorium after attachment to the leaf surface and germination of the spore. This infection structure is an essential prerequisite for a successful infection, allowing the fungus to penetrate the plant cuticle in a direct manner by mechanical force. ${ }^{3}$ Therefore, an intact melanin layer is essential for appressorial turgor generation. Melanin-deficient mutants, for example, ALB1, BUF1 and RSY1, fail to generate appressorial turgor and are nonpathogenic. ${ }^{4}$

In $M$. oryzae, tetrahydroxynaphthalene or trihydroxynaphthalene reductases are targets for the successful and widely used plant protectants, such as tricyclazole and carpropamid. ${ }^{5}$ Inhibitors of melanin biosynthesis are excellent examples for plant protectants interfering with the infection-related morphogenesis but not with vegetative growth.

To control rice blast, quinone outside inhibiting fungicides are increasingly applied in Japan. Such quinone outside inhibiting fungicides are threatened by resistance development in target pathogens. ${ }^{6}$ As M. oryzae is considered as a 'high-risk' pathogen in terms of resistance to quinone outside inhibiting fungicides, inhibition of targets, essential for differentiation processes and pathogenicity, provides interesting alternatives for plant protection strategies.
Fungi are known to be a rich source for inhibitors of the infectionrelated morphogenesis in phytopathogenic fungi. In this paper, we describe the producing organism, its cultivation and isolation of caripyrin (trans-5-(3-methyloxiranyl)pyridincarboxylic acid methyl ester 1), a new pyridyloxirane and its biological activities.

\section{MATERIALS AND METHODS}

\section{Microorganisms}

Producing organism. Caripia montagnei IBWF-A24-2006 was isolated from spore prints of fruiting bodies growing on decaying wood collected in French Guiana. Methods and reagents for DNA extraction and PCR amplification of the internal transcribed spacer region 1 (primers ITS1F and ITS4B) and the $5^{\prime}$ end of the $18 \mathrm{~S}$ ribosomal RNA gene were as described previously. ${ }^{7}$

The strain was maintained at $22^{\circ} \mathrm{C}$ on yeast malt glucose (YMG) medium composed of yeast extract $4 \mathrm{~g}$ (Hartge Incredients, Hamburg, Germany), malt extract $10 \mathrm{~g}$ (Fränkle \& Eck, Fellbach, Germany), glucose $4 \mathrm{~g}$ and agar $20 \mathrm{~g}$ per 11 tap $\mathrm{H}_{2} \mathrm{O}$. The $\mathrm{pH}$ was adjusted with $1 \mathrm{~N} \mathrm{HCl}$ to 5.5. Mycelial cultures of C. montagnei are deposited in the culture collection of the Institute of Biotechnology and Drug Research (IBWF e.V.).

Test organisms. M. oryzae strain 70-15 was obtained from the Fungal Genetics Stock Centre, Kansas City, KS, USA. The strain was maintained on CM medium as described. ${ }^{2}$ Fusarium graminearum, Botrytis cinerea and Phytophthora infestans were provided by BASF SE.

\section{Fermentation and isolation}

Fermentations were carried out in YMG medium in a 201 fermentor (Biostat A-20, Braun Melsungen, Melsungen, Germany) at $28^{\circ} \mathrm{C}$ with aeration $\left(5.01 \mathrm{~min}^{-1}\right)$ and agitation ( 150 r.p.m.). A well-grown culture (1l) in the same medium was used as inoculum. During fermentation, samples were taken daily 
to monitor the appearance of $\mathbf{1}$ in the broth by analytical HPLC as described below. After 16 days of fermentation, when the concentration of $\mathbf{1}$ had reached maximum and the glucose in the medium was consumed, the culture fluid (81) was separated from the mycelia and extracted with an equal volume of ethyl acetate. The mycelium containing no active compounds was discarded. The organic extract was dried with $\mathrm{Na}_{2} \mathrm{SO}_{4}$ and concentrated to yield $1.2 \mathrm{~g}$ of crude product, which was further purified by silica gel chromatography (silica gel 60, 63-200 $\mu \mathrm{m}, 40 \mathrm{~g}$, column size $24 \times 4.5 \mathrm{~cm}$; Merck, Darmstadt, Germany). Elution with cyclohexane-ethyl acetate (7:3) yielded $190 \mathrm{mg}$ of an intermediate product. Final purification was achieved by HPLC using a Nucleosil 100-5 C18 column $(21 \times 250 \mathrm{~mm}, 5 \mu \mathrm{m}$; Merck). Elution was carried out with $32 \% \mathrm{MeCN}$ in $\mathrm{H}_{2} \mathrm{O}$ at a flow rate of $15 \mathrm{ml} \mathrm{min}^{-1}$. HPLC was performed in a preparative Jasco modular HPLC system (Jasco, Gross-Umstadt, Germany) consisting of two binary pumps (PU-1586) and a multi-wavelength detector UV-1570M. HPLC for daily samples was performed on an Agilent 1100 Series (Agilent Technologies, Waldbronn, Germany) with a LiChrospher 100 C18 column $(125 \times 4 \mathrm{~mm}, 5 \mu \mathrm{m}$, Merck).

\section{Biological assays}

Inhibition of conidial germination and appressorium formation. Conidia from M. oryzae were harvested by centrifugation $\left(1000 \mathrm{~g} \mathrm{~min}^{-1}\right)$ and suspended in distilled $\mathrm{H}_{2} \mathrm{O}$ to a concentration of $5 \times 10^{5}$ conidia per ml. Assays were carried out in 24-well microtiter plates (Sarstedt, Nuremberg, Germany) with $2.5 \times 10^{4}$ conidia per $\mathrm{ml}$ of distilled $\mathrm{H}_{2} \mathrm{O}$. After $16 \mathrm{~h}$ incubation at $28^{\circ} \mathrm{C}$, germinated conidia were counted using an inverted microscope (Leica DM IRB, Leica, Wetzlar, Germany). The tests were carried out in triplicates and 300 conidia were counted.

Nematicidal activity against Caenorhabditis elegans and cytotoxic activity against Hep G2-cells was assessed as described previously. ${ }^{7,8}$ Antibacterial activity against Bacillus brevis, B. subtilis, Micrococcus luteus and Enterobacter dissolvens was determined in a serial dilution assay as described previously. ${ }^{9}$

To test the protective effect of $\mathbf{1}$ and fusaric acid (2), $10 \mathrm{ml}$ of the solution with $5 \times 10^{4}$ spores per $\mathrm{ml}, 0,2 \%$ gelatine and the respective compound were sprayed on 21-day-old plants of Oryza sativa CO-39. For this assay, concentrations between 10 and $100 \mu \mathrm{g} \mathrm{ml}^{-1}$ were used for $\mathbf{1}$ and 2 . The treated plants were incubated for $24 \mathrm{~h}$ at $27^{\circ} \mathrm{C}$ and $80 \%$ humidity in plastic bags (RotilaboKordelzugbeutel, Carl Roth GmbH + Co. KG, Karlsruhe, Germany) in an environmental test chamber (Versatile Environmental Test Chamber MLR$350 \mathrm{H}$, Sanyo Electric, Munich, Germany). Then, the plants were taken, sprayed with $\mathrm{H}_{2} \mathrm{O}$ and incubated for another $72 \mathrm{~h}$ under the same conditions. The assay was evaluated by counting the lesions per plant and compared with the control after a total of $96 \mathrm{~h}$. In addition, a leaf segment assay was conducted as described previously. ${ }^{8}$

\section{Phytotoxic activity}

The phytotoxicity was monitored using a droplet assay with leaves of 28-dayold O. sativa CO-39. Leaves were fixed on agar plates and inoculated with droplets of $9 \mu \mathrm{l}$ of sterile gelatine $(0.2 \%)$ solution and $1 \mu \mathrm{l}$ of $\mathrm{MeOH}$ and $\mathbf{1}$ or $\mathbf{2}$ in different concentrations. Toxicity was evaluated after 7 days under the microscope and compared with the control containing $\mathrm{MeOH}$.

Toxicity on seeds was measured using a germination assay with seeds of O. sativa CO-39, Lepidium sativum and Triticum aestivum RIBAND. Seeds were grown in sterile 24 -well plates on filter papers with 5 and $50 \mu \mathrm{g}$ of $\mathbf{1}$ or $\mathbf{2}$ in $500 \mu \mathrm{l}$ $\mathrm{H}_{2} \mathrm{O}$. Toxic effects on T. aestivum and O. sativa were evaluated after 8 days at $27^{\circ} \mathrm{C}$ by measuring the length of sprouts and roots compared with the control grown in $\mathrm{H}_{2} \mathrm{O}$. Inhibitory activity against germinating seed of $L$. sativum and Setaria italica was assessed after 3-day growth in darkness and 1 day in light at $27^{\circ} \mathrm{C}$.

\section{Inhibition of respiration}

Inhibition of mitochondrial respiration, that is, oxygen-uptake from oxygen-saturated cell suspensions, was measured polarographically with a Clark electrode. The assay was carried out as described by Strathkelvin Instruments with an Oxigen MeterModel 782 (Fa. Strathkelvin Instruments, North Lanarkshire, Scotland). Strobilurin A was used as a positive control. The compounds were tested up to a concentration of $100 \mu \mathrm{g} \mathrm{ml}^{-1}$ with conidia of M. oryzae.

\section{General methods}

The melting point was determined using a Dr Tottoli apparatus (Büchi AG, Flawil, Switzerland) and is uncorrected. The optical rotation was measured with a Krüss P8000 polarimeter (KRÜSS Optronic GmbH, Hamburg, Germany) at $589 \mathrm{~nm}$. UV and IR spectra were measured with a Perkin-Elmer Lambda-16 spectrophotometer (Perkin-Elmer, Waltham, MA, USA) and a Bruker IFS48 FTIR spectrometer (Bruker, Ettlingen, Germany), respectively. NMR spectra were recorded with a Bruker AMX 400 spectrometer. The spectra were measured in $\mathrm{CDCl}_{3}$ and the chemical shifts were referenced to the residual solvent signal $\left(\mathrm{CDCl}_{3}: \delta_{\mathrm{H}}=7.26\right.$ p.p.m., $\delta_{\mathrm{C}}=77.16$ p.p.m. $\left.{ }^{10}\right)$. Electrospray ionization (ESI)-MS spectra were recorded on a Finnigan Mat95 spectrometer (Finnigan MAT GmbH, Bremen, Germany). ESI-high-resolution mass spectra were recorded on a MicroMass/Waters ESI Q-TOF mass spectrometer (MicroMass/Waters, Milford, MA, USA) equipped with a LockSpray interface using $\mathrm{NaI} / \mathrm{CsI}$ or trialkylamines as external reference.

\section{Caripyrin A}

Cream-colored solid, m.p. $43-45^{\circ} \mathrm{C} .[\alpha]_{\mathrm{D}}^{25}+25.6\left(\right.$ c $\left.0.75, \mathrm{CDCl}_{3}\right)$. UV $\lambda_{\max }^{\mathrm{MeOH}}$ $(\log \varepsilon) 223(\mathrm{sh}, 3.83) \mathrm{nm}, 236(3.98) \mathrm{nm}, 271(3.70) \mathrm{nm}$ and $278(\mathrm{sh}, 3.42) \mathrm{nm}$. IR $v_{\max }(\mathrm{KBr})\left(\mathrm{cm}^{-1}\right) 3442,2956,1725,1438,1312,1024$ and $709 .{ }^{1} \mathrm{H}$ NMR $\left(400 \mathrm{MHz}, \mathrm{CDCl}_{3}\right) \delta 8.67(\mathrm{~d}, J=2.2 \mathrm{~Hz}, 6-\mathrm{H}), 8.10(\mathrm{~d}, J=8.1 \mathrm{~Hz}, 3-\mathrm{H}), 7.67(\mathrm{dd}$, $J=8.1,2.2 \mathrm{~Hz}, 4-\mathrm{H}), 4.00\left(\mathrm{~s}, \mathrm{OCH}_{3}\right), 3.68\left(\mathrm{~d}, J=1.9 \mathrm{~Hz}, 2^{\prime}-\mathrm{H}\right), 3.06(\mathrm{qd}, J=5.1$, $\left.1.9 \mathrm{~Hz}, 3^{\prime}-\mathrm{H}\right)$ and $1.50\left(\mathrm{~d}, J=5.1 \mathrm{~Hz}, 3^{\prime}-\mathrm{CH}_{3}\right) .{ }^{13} \mathrm{C} \mathrm{NMR}\left(101 \mathrm{MHz}, \mathrm{CDCl}_{3}\right) \delta$ $165.6(\mathrm{C}=\mathrm{O}), 147.9(\mathrm{C}-6), 147.7(\mathrm{C}-2), 137.6(\mathrm{C}-5), 133.9(\mathrm{C}-4), 125.1(\mathrm{C}-3)$, $59.8\left(\mathrm{C}-3^{\prime}\right), 57.0\left(\mathrm{C}-2^{\prime}\right), 53.1\left(\mathrm{OCH}_{3}\right)$ and $18.0\left(3^{\prime}-\mathrm{CH} 3\right)$. ESI-MS m/z $193.9(10)$ $[\mathrm{M}+\mathrm{H}]^{+}, 215.9(100)[\mathrm{M}+\mathrm{Na}]^{+}, 231.9(42)[\mathrm{M}+\mathrm{K}]^{+}$and $409.0(23)[2 \mathrm{M}+\mathrm{Na}]^{+}$. ESI-HRMS $m / z 216.0631$ (calcd for $\mathrm{C}_{10} \mathrm{H}_{11} \mathrm{NO}_{3}+\mathrm{Na}^{+}$216.0637).

\section{RESULTS}

\section{Producing organism}

The fruiting bodies of C. montagnei IBWF-A24-2006 showed all morphological characteristics of the genus and species as described. ${ }^{11}$ The internal transcribed spacer region 1 sequence of the $5.8 \mathrm{~S}$ ribosomal RNA gene was identical to the sequence published for C. montagnei in the GenBank. ${ }^{12}$

\section{Fermentation of $C$. montagnei IBWF-A24-2006 and isolation of 1} To optimize fermentation conditions for the biosynthesis of bioactive compounds, strain IBWF-A24-2006 was cultured in several media. The highest production rate for the bioactive constituent was found in YMG medium at high agitation (150 r.p.m.). At lower agitation rates, the fungus failed to produce $\mathbf{1}$ in submerged culture. A fermentation diagram for a submerged culture of C. montagnei is shown in Figure 1. After $\sim 4-5$ days of fermentation the production of 1 started while glucose and to a lower extent maltose were consumed. Fermentations were stopped when the glucose in the medium was consumed and the production rate had reached its maximum. Bioactivity-guided isolation led to the isolation of $10.1 \mathrm{mg}$ of a novel compound, which we named caripyrin (1).

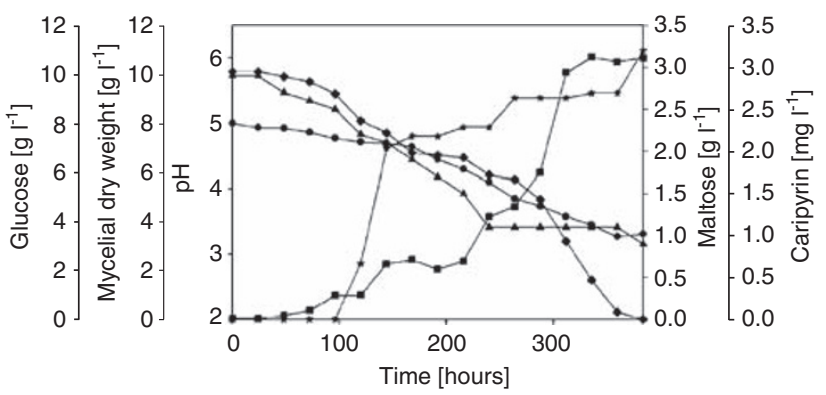

Figure 1 Fermentation of caripyrin-producing strain Caripia montagnei IBWF-A24-2006 in yeast malt glucose medium. - $-\mathrm{pH} ;-$ mycelial dry weight; $\multimap$ glucose; $\longleftarrow$ maltose; $\multimap$ caripyrin. 
1<smiles>COC(=O)c1ccc(C2OC2C)cn1</smiles><smiles>CCCCc1ccc(C(=O)O)nc1</smiles>

Figure 2 Structure of caripyrin (1) and fusaric acid (2).

\section{Structure elucidation}

Mass spectrometric data gave an elemental composition of $\mathrm{C}_{10} \mathrm{H}_{11} \mathrm{NO}_{3}$, requiring five double bond equivalents. The ${ }^{13} \mathrm{C} \mathrm{NMR}$ spectrum indicated three methine carbons at 147.9, 133.9 and 125.1 p.p.m. along with two quaternary carbons at 147.7 and 137.6 p.p.m. The HETCOR showed that the protons corresponding to these methine carbons resonated at downfield chemical shifts. These data strongly suggested a 2,5-disubstituted pyridine core, with an acceptor group bound to C-2. This substituent proved to be a methyl ester, apparent from a carbonyl group at 165.6 p.p.m. and a methoxy group at 53.1 p.p.m. (similar to methyl fusarate). ${ }^{13}$

The substituent at C-5 was a propyl chain with two downfieldshifted carbons, and the characteristic coupling constant between the two methine protons of $1.9 \mathrm{~Hz}$ indicated the presence of a transconfigured epoxide. The diol formally resulting from hydrolysis of $\mathbf{1}$ has been described as CJ-14877 from Marasmiellus sp., ${ }^{14}$ whereas to the best of our knowledge, the only example of an oxirane-substituted pyridine of natural origin is epoxy-6,7-racemigerine, which was isolated from Scaevola racemigera. ${ }^{15}$ Figure 2 gives the structure of 1 and 2.

\section{Biological activity of 1}

In a screening for inhibitors of infection-related differentiation processes in $M$. oryzae, extracts of the basidiomycete C. montagnei IBWF-A24-2006 were found to interfere with conidial germination. Compound 1 isolated from these extracts was found to inhibit conidial germination in the rice blast fungus, whereas differentiation processes in B. cinerea, $P$. infestans and F. graminearum were not affected up to $100 \mu \mathrm{g} \mathrm{ml}^{-1}$. In contrast, the structurally closely related fungal metabolite $\mathbf{2}$ interfered with spore germination in P. infestans and F. graminearum. The results of the spore germination assays are summarized in Table 1.

Caripyrin (1) prevented germination of $M$. oryzae conidia more efficiently than 2 . In total, $90 \%$ of the $M$. oryzae conidia failed to germinate at $5 \mu \mathrm{g} \mathrm{ml}^{-1}$ of $\mathbf{1}$, whereas $50 \mu \mathrm{g} \mathrm{ml}^{-1}$ of 2 was needed for a comparable level of inhibition. In contrast, 2 was found to inhibit spore germination in F. graminearum and, more efficiently, in P. infestans.

Interestingly, conidial germination in M. oryzae in CM medium was not affected by $\mathbf{1}$. Under these conditions, 1 was ineffective even at concentrations exceeding the inhibitory concentration in $\mathrm{H}_{2} \mathrm{O}$. However, conidial germination in $M$. oryzae in $\mathrm{H}_{2} \mathrm{O}$ on treatment with $\mathbf{1}$ was not restored by addition of the constituents of $\mathrm{CM}$ medium such as peptone, glucose, yeast extract, nitrate salts or trace element solution. Addition of single amino acids such as L-cysteine did not reduce the biological activity of $\mathbf{1}$ in equimolar concentrations (data not shown).
Table 1 Inhibitory effect of caripyrin and fusaric acid (ED, $\mu \mathrm{g} \mathrm{m}^{-1}$ ) on conidial germination and vegetative growth of sprout and root of plant seed

\begin{tabular}{|c|c|c|c|c|}
\hline \multirow[b]{2}{*}{ Test organism } & \multicolumn{2}{|c|}{ Caripyrin } & \multicolumn{2}{|c|}{ Fusaric acid } \\
\hline & $E D_{50}$ & $E D_{100}$ & $E D_{50}$ & $E D_{100}$ \\
\hline \multicolumn{5}{|l|}{ Plants } \\
\hline Lepidium sativum & 5 & $>50$ & $<5$ & $<5$ \\
\hline Oryza sativa & 5 & $>50$ & 5 & $>50$ \\
\hline Triticum aestivum & $>50$ & $>50$ & $<50$ & $>50$ \\
\hline \multicolumn{5}{|l|}{ Fungi } \\
\hline Fusarium graminearum & $>100$ & $>100$ & $>50$ & 100 \\
\hline Magnaporthe grisea & $<5$ & 10 & 20 & 40 \\
\hline Phytophthora infestans & $>100$ & $>100$ & $>10$ & 20 \\
\hline
\end{tabular}

Abbreviation: ED, effective dose.

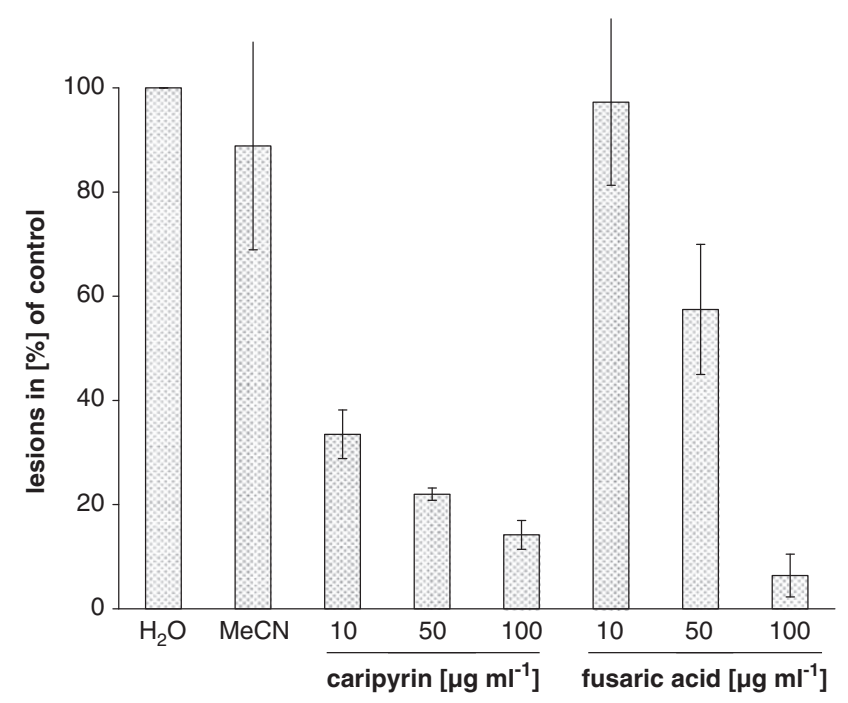

Figure 3 Protective effect of caripyrin and fusaric acid on $O$. sativa against the phytopathogenic fungus $M$. oryzae.

Plant protective activity in spray tests

To investigate the plant protective potential of $\mathbf{1}$ in comparison with $\mathbf{2}$, rice plants were sprayed with conidia of $M$. oryzae and the compounds. As shown in Figure 3, 1 was more effective than 2. Treatment with a $10 \mu \mathrm{g} \mathrm{ml}^{-1}$ solution of $\mathbf{1}(10 \mathrm{ml})$ reduced the number of lesions to $50 \%$, whereas application of $10 \mathrm{ml}$ of a $50 \mu \mathrm{g} \mathrm{ml}^{-1}$ solution reduced the number of disease symptoms by $80 \%$. However, total protection was not observed. The same amount of $\mathbf{2}$ was hardly effective.

Phytotoxic activities toward O. sativa, L. sativum and T. aestivum were recorded for both compounds. As shown in Figure 4, at $50 \mu \mathrm{g} \mathrm{ml}^{-1}$ root length in O. sativa was reduced by $60 \%$ when exposed to caripyin (1) and by $90 \%$ when treated with 2 . The sprout length was less affected at the same concentrations. A reduction in length of $30 \%$ was observed when treated with 1 and $50 \%$ when incubated with 2 . Effects on growth of L. sativum and T. aestivum were similar to those observed for rice (data not shown).

\section{Further biological activities}

In a cytotoxicity assay with HepG2 cells, 1 did not show toxic activity at a concentration of $100 \mu \mathrm{g} \mathrm{ml}^{-1}$. ${ }^{16}$ At the same concentration, no antibacterial activity against $B$. brevis, B. subtilis, $M$. luteus and $E$. dissolvens was observed in a serial dilution assay for both 


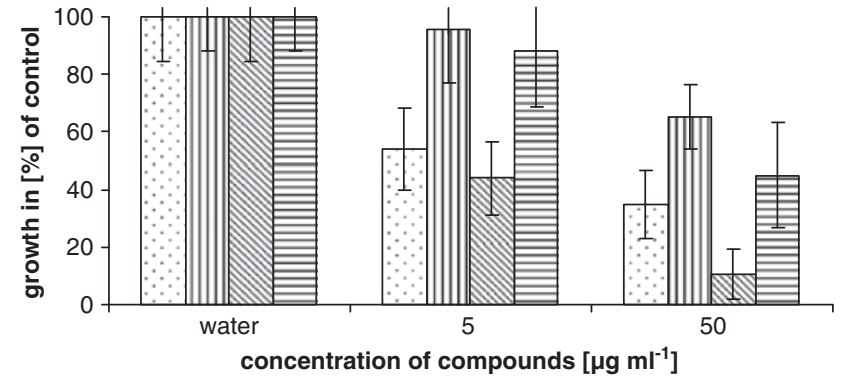

Figure 4 Growth of root $\square \mathbb{Q}$ and sprout 皿目 of $O$. sativa when treated

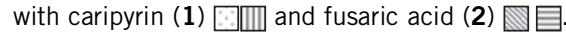

compounds. In contrast to $2,{ }^{17} \mathbf{1}$ was not found to inhibit respiration in $M$. oryzae, in conidia or in mycelia. Furthermore, no nematicidal activity toward C. elegans was found.

\section{DISCUSSION}

Conidial germination is an initial step in the infection process of many phytopathogenic fungi and subsequently essential for a successful colonization of host plants. Therefore, inhibition of this early differentiation process offers potential targets for plant protection strategies with specific and environmentally safe fungicides. ${ }^{18}$ In screening extracts of the basidiomycetes, C. montagnei IBWF-A24-2006 were found to inhibit conidial germination in $M$. oryzae, whereas vegetative growth was not affected. The producing organism, C. montagnei, is a fungus occasionally seen in forests forming club-shaped, flat-topped white fruiting bodies on dead branches. The fungus was identified on the basis of its morphological features and by a genetic analysis. The internal transcribed spacer sequence of our C. montagnei shows high sequence homology to other basidiomycetes, such as Micromphale brassicolens and Gymnopus iocephalus, and to a shorter sequence of another strain of the species (data not shown). To date no secondary metabolites have been recorded from this species. ${ }^{19}$

Caripyrin (1), a structurally new pyridyloxirane, was identified in this study as specific inhibitor of conidial germination in the rice blast fungus $M$. oryzae. It was produced in submerged cultures with high agitation in YMG medium. The compound is structurally closely related to 2, a fungal secondary metabolite identified from other fungal species belonging to the genus Fusarium, but not from basidiomycetes. ${ }^{20}$

Fusaric acid (2) has been described to be produced in Fusarium verticillioides under stress conditions, notably, nutrient limitations. ${ }^{21}$ The metabolite has been described as an inhibitor of metal-containing oxidative enzymes, such as dopamine- $\beta$-hydroxylases, phenylethanolamine methyltransferase and catechol oxidase. ${ }^{22}$ Nonpathogenic Fusarium oxysporum species have been described as an potential biocontrol agents, producing only 2 and dehydrofusaric acid, but no other toxins. ${ }^{23}$ An antifungal activity toward $P$. infestans has recently been reported. ${ }^{24}$ Whether 2 is required for the antagonistic interaction remains to be elucidated. In this study, we found that 2 prevents spore germination in our $F$. graminearum strain, but fails to inhibit vegetative growth of all fungal test organisms.

In contrast to $2, \mathbf{1}$ is produced in complex media before nutrient limitation. Caripyrin (1) was found to inhibit conidial germination in M. oryzae under conditions resembling those found on the plant surface. Neither vegetative growth nor differentiation processes in all other fungi tested were affected. Such selectivity matches the requirements for a modern plant protectant because of the low toxicological impact on other fungi. When C. montagnei was tested for antagonistic activity toward phytopathogenic fungi, neither $M$. oryzae nor $F$. graminearum, nor B. cinerea were inhibited.

The protection of host plants from fungal colonization was more efficient for $\mathbf{1}$ compared with $\mathbf{2}$. Compound $\mathbf{1}$ was found to reduce the number of lesions caused by the rice blast fungus on rice leaves, but a complete protection of the plants has not been observed. Therefore, the compound does not seem to be a promising candidate for the development of an agro fungicide.

Phytotoxic effects have been observed in seeds of rice, wheat and L. sativum when exposed to $\mathbf{1}$ or $\mathbf{2}$. However, all seed/plants used were less susceptible to 1 than to 2 . Phytotoxic activity has been reported for 2 toward Lemna minor, Oryza sp. and other plants. ${ }^{25,26}$ It was found that the metabolite could elicit various plant defense responses at a concentration of $100 \mathrm{~nm}$ without toxic effects in Arabidopsis thaliana cell cultures. ${ }^{27}$ Addition of L-cysteine in equimolar concentrations did not reduce the biological activity of $\mathbf{1}$. Thus, the epoxide moiety does not seem to be responsible for the activity against Magnaporthe grisea.

\section{ACKNOWLEDGEMENTS}

This work was financially supported by the state of Rheinland-Pfalz and BASF SE. We are grateful to Dr John Speakman, BASF SE, for some of the fungal strains used as test organism in this study. We thank Anja Meffert for expert technical assistance. We thank Dr V Sinnwell (University of Hamburg) for NMR spectroscopic analyses, as well as Dr S Franke (University of Hamburg) and Dr N Hanold (University of Mainz) for mass spectrometry. Helpful discussions with $\mathrm{H}$ Kolshorn (University of Mainz) are gratefully acknowledged.

1 Oerke, E. C., Dehne, H. W., Schonbeck, F. \& Weber, A. Crop Protection \& Crop Production. 808 pp (Elsevier, Amsterdam, 1994).

2 Talbot, N. J., Ebbole, D. J. \& Hamer, J. E. Identification and characterization of MPG1, a gene involved in pathogenicity from the rice blast fungus Magnaporthe grisea. Plant Cell 5, 1575-1590 (1993)

3 Howard, R. J., Ferrari, M. A., Roach, D. H. \& Money, N. P. Penetration of hard surfaces by a fungus employing enormous turgor pressures. Proc. Natl Acad. Sci. USA 88, 11281-11284 (1991).

4 Howard, R. J. \& Ferrari, M. A. Role of melanin in appressorium function. Exp. Mycol. 13, 403-418 (1989).

5 Thompson, J. E. et al. The second naphthol reductase of fungal melanin biosynthesis in Magnaporthe grisea. J. Biol. Chem. 275, 34867-34872 (2000).

6 Wei, C. Z., Katoh, H., Nishimura, K. \& Ishii, H. Site-directed mutagenesis of the cytochrome b gene and development of diagnostic methods for identifying Qol resistance of rice blast fungus. Pest Manag. Sci. 65, 1344-1351 (2009).

7 Schwarz, M., Köpcke, B., Weber, R. W. S., Sterner, O. \& Anke, H. 3-Hydroxypropionic acid as a nematicidal principle of endophytic fungi. Phytochemistry 65, 2239-2245 (2004).

8 Kettering, M., Valdivia, C., Sterner, O., Anke, H. \& Thines, E. Heptemerones A-G, seven novel diterpenoids from Coprinus heptemerus: producing organism, fermentation, isolation and biological activities. J. Antibiot. 58, 390-396 (2005).

9 Anke, H., Bergendorff, O. \& Sterner, O. Assay of the biological activity of guaiane sesquiterpenoids isolated from the fruit bodies of edible Lactarius species. Food Chem. Toxicol. 27, 393-398 (1989).

10 Gottlieb, H. E., Kotlyar, V. \& Nudelman, A. NMR chemical shifts of common laboratory solvents as trace impurities. J. Org. Chem. 62, 7512-7515 (1997).

11 Singer, R. The Agaricales in Modern Taxonomy (Koeltz Scientific Books, Königsstein, Germany, 1986).

12 National Center for Biotechnology Information (NCBI), accession number DQ449988, 2009.

13 Renslo, A. R. \& Danheiser, R. L. Synthesis of substituted pyridines via regiocontrolled [4+2] cycloadditions of oximinosulfonates. J. Org. Chem. 63, 7840-7850 (1998).

14 Ichikawa, K., et al. Novel cytokine production inhibitors produced by a basidiomycete, Marasmiellus sp. J. Antibiot. 54, 703-709 (2001).

15 Skaltsounis, A. L. et al. Plantes de Nouvelle-Calédonie. 94e Communication. Alcaloïdes monoterpéniques de Scaevola racemigera DÄNIKER. Helv. Chim. Acta. 68, 1679-1685 (1985).

16 Fernandez-Pol, J. A., Klos, D. J. \& Hamilton, P. D. Cytotoxic activity of fusaric acid on human adenocarcinoma cells in tissue culture. Anticancer Res. 1, 57-64 (1993).

17 Hirai, T., Fukushima, K., Kumamoto, K. \& Iwahashi, H. Effects of some naturally occurring iron ion chelators on in vitro superoxide radical formation. Biol. Trace Elem. Res. 108, 77-85 (2005). 
18 Thines, E., Anke, H. \& Weber, R. W. S. Fungal secondary metabolites as inhibitors of infection-related morphogenesis in phytopathogenic fungi. Mycol.Res. 108, 14-25 (2004).

19 Chapman \& Hall Database 2010.

20 Bacon, C. W., Porter, J. K., Norred, W. P. \& Leslie, J. F. Production of fusaric acid by Fusarium species. Appl. Environ. Microbiol. 62, 4039-4043 (1996).

21 Choi, Y- E. et al. AC1, a gene encoding a putative GTPase-activating protein, regulates bikaverin biosynthesis in Fusarium verticillioides. Mycologia 100, 701-709 (2008).

22 Jain, M. Handbook of Enzyme Inhibitors (John Wiley \& Sons, New York, 1982).

23 Alabouvette, C. et al. Diversity and interactions among strains of Fusarium oxysporum: application to biological control. In Biotic Interactions in Plant Pathogen Associations (eds Jegger, M. J. \& Spence, N. J.) 131-157 (CAB International, London, 2001).
24 Son, S. W. et al. Bikaverin and fusaric acid from Fusarium oxysporum show antioomycete activity against Phytophthora infestans. J. Appl. Microbiol. 104, 692-698 (2008).

25 Vesondern, R. F., Labeda, D. P. \& Peterson, R. E. Phytotoxic activity of selected $\mathrm{H}_{2} \mathrm{O}-$ soluble metabolites of Fusarium against Lemna minor L. (Duckweed). Mycopathologia 118, 185-189 (1992).

26 Iwahashi, H., Kawamori, H. \& Fukushima, K. Quinolinic acid, alpha-picolinic acid, fusaric acid, and 2,6-pyridinedicarboxylic acid enhance the Fenton reaction in phosphate buffer. Chem. Biol. Interact. 118, 201-215 (1999).

27 Bouizgarne, B. et al. Early physiological responses of Arabidopsis thaliana cells to fusaric acid: toxic and signalling effects. New Phytol. 169, 209-218 (2006). 